\title{
Overload in the roof trusses of the Media Center building in Saransk
}

\author{
Elvira Egereva ${ }^{1, *}$, Alexei Barmenkov ${ }^{2}$ \\ ${ }^{1}$ Moscow State University of Civil Engineering, Yaroslavskoe shosse, 26, Moscow, 129337, Russia \\ ${ }^{2}$ National Research Mordovia State University, MRSU, Bolshevistskaya str., 68, Saransk, Republic of \\ Mordovia, 430005
}

\begin{abstract}
The possibility of applying overload to the nodes of the bottom chord of the roof trusses of the Media Center building constructed as a part of the design of the temporary buildings and structures for the preparation and holding of the World Football Cup in the Russian Federation (Saransk) in 2018 is studied in the article. A variant of fixing the load with the help of the universal mounting is developed.
\end{abstract}

\section{Introduction}

After the end of the World Cup 2018 in Russia, a rich legacy in the form of sports facilities and infrastructure remained. For infrastructure facilities, it was immediately clear that they would continue to serve the benefit of the population of the organizing city: hotels will be partially transferred to the housing stock, improvement of the city will contribute to a more progressive cultural rest for citizens and tourists, new roads and interchanges will significantly reduce the time on the road and significantly reduce the transport load on the existing network, newly built or reconstructed facilities, such as the airport in the city of Saransk, will allow relocating with minimal time between cities.

The situation with sports objects, is different a little. Tremendous stadiums, designed for tens of thousands of spectators, are currently not as popular as during the championship, and facilities for auxiliary purposes: press centers, media centers, fan passport issuing centers, etc. are generally empty. In order to get benefit out of empty space, the operating organizations received the right to rent out part of the auxiliary buildings for mass cultural events.

Since mass events envisage performance on the speaker's stage, and the stage, in turn, provides for suspended light and sound equipment, it became necessary to carry out activities for the preparation of truss structures for additional load application.

Thus, there is a relevance of the development of design solutions in terms of the application of additional load on the trusses. Let us consider the possibility of applying additional load to the nodes of the lower belt of the roof trusses of the Media Center building built as a part of the design of temporary buildings and structures for the preparation and holding of the World Cup in the Russian Federation (Saransk) in 2018.

\footnotetext{
*Corresponding author: egerevaen@mail.ru
} 


\section{Materials and Methods}

The possibility of applying additional loads on building structures in connection with the suspension or support of rigging means is determined by appropriate calculations and measures are taken to exclude the possibility of damage to building structures.

The nature of the application of the additional load is stationary, since the action planes of the bending moment and lateral force rotate together with the joint. To calculate the additional load, do the following: collect the load on the existing system, determine the additionally applied loads (size, location), determine the internal forces arising in the rods of the truss from the combined effect of the design and additionally applied loads, determine the load-carrying capacity of the nodes the farm connections, taking into account the additionally applied load, with a positive result of the calculation of the possibility of applying additional load and develop a mounting option.

The settlement mechanism is adopted in accordance with the joint venture 16.13330.2011 Updated version of SNiP II-23-81 "Steel structures". To determine the internal efforts, the program complex LIRA-SAPR R 2013 has been adopted.

\section{Results}

We will check the carrying capacity of roof trusses of the Media Center building in the city of Saransk. Rafter trusses are made of galvanized thin-walled steel profiles with a C-shaped section. The verification of the carrying capacity of roof trusses is carried out in order to determine the possibility of applying additional nodal loads.

The initial data was the working documentation "Design of buildings and temporary facilities for the preparation and holding of the World Cup in 2018 in the Russian Federation. Media Center 40x70m, Saransk" in terms of sections: metal structures, metal structures, metal structures, as well as measurement drawings [1-6].

As a result of the analysis of the documentation, it was established:

- span of the farm - $20 \mathrm{~m}$;

- farm shed;

- construction area: Saransk;

- estimated snow load is $210 \mathrm{~kg}$ / sq. m. according to SP 20.13330.2016 [3];

- material of the main elements of the truss - steel grade S350 (S345) in accordance with GOST R 52246-2004;

- material gussets - steel S255 GOST 27772-88;

- bolts M16, strength class 5.8;

- step farms - 5 meters;

- roof - roofing sandwich panels with a thickness of $100 \mathrm{~mm}[1,7]$;

- girders - zet-shaped section, thin-walled, made of galvanized steel.

In the extreme, panels of the upper belt are taken outside the nodal load application.

The design scheme of the trusses and the magnitude of the nodal loads are shown in Figure. 1. The design cross-sections of the elements of the truss trusses are shown in Table 1 and Figures 3-5. 


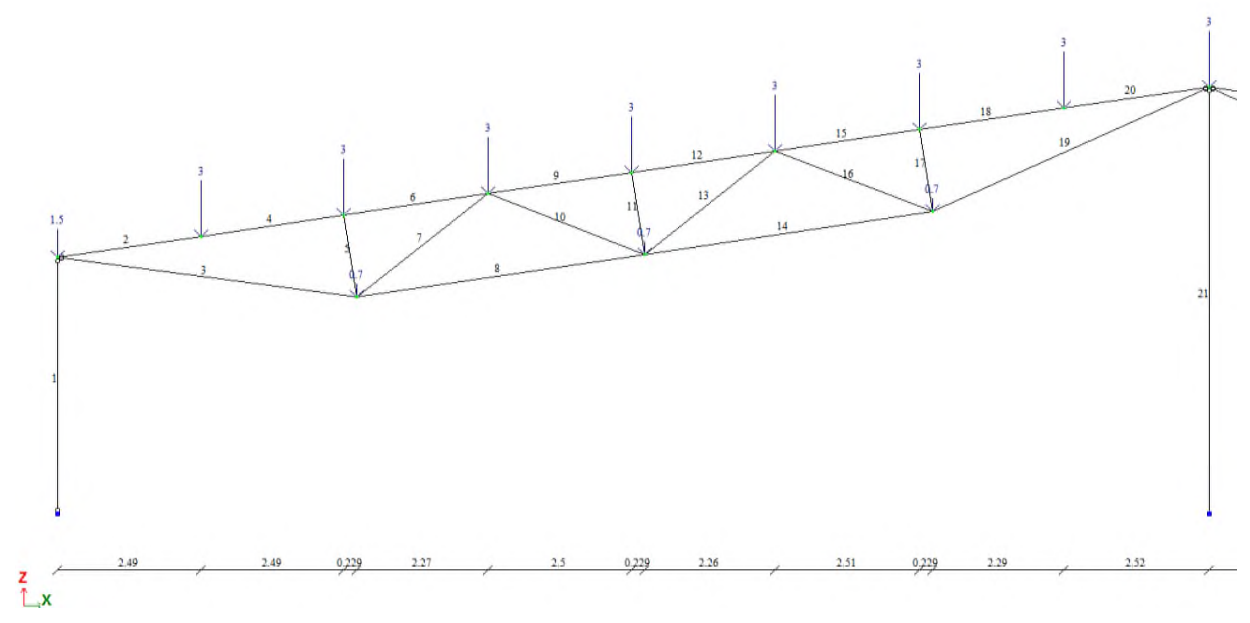

Fig. 1. A symmetrical fragment of a farm. Driving loads of applications

Determination of efforts in the elements of roof trusses was carried out on a computer using the LIRA-SAPR R 2013 software package.

Table 1. The type and size of the cross section of the belts and grille farm

\begin{tabular}{|c|l|}
\hline Item type & Section type \\
\hline Upper belt & Twin C-profiles \\
& $400 \times 90 \times 22 \times 3.0$ \\
\hline Lower belt & Twin C-profiles \\
& $250 \times 90 \times 20 \times 2.5$ \\
\hline Central pillar & Twin C-profiles \\
& $200 \times 80 \times 20 \times 2.5$ \\
\hline Stands & Twin C-profiles \\
& $200 \times 80 \times 20 \times 2.0$ \\
\hline Bracing extreme & Twin C-profiles \\
& $250 \times 90 \times 20 \times 2.5$ \\
\hline Bracing & Twin C-profiles \\
& $200 \times 80 \times 20 \times 2.0$ \\
\hline
\end{tabular}

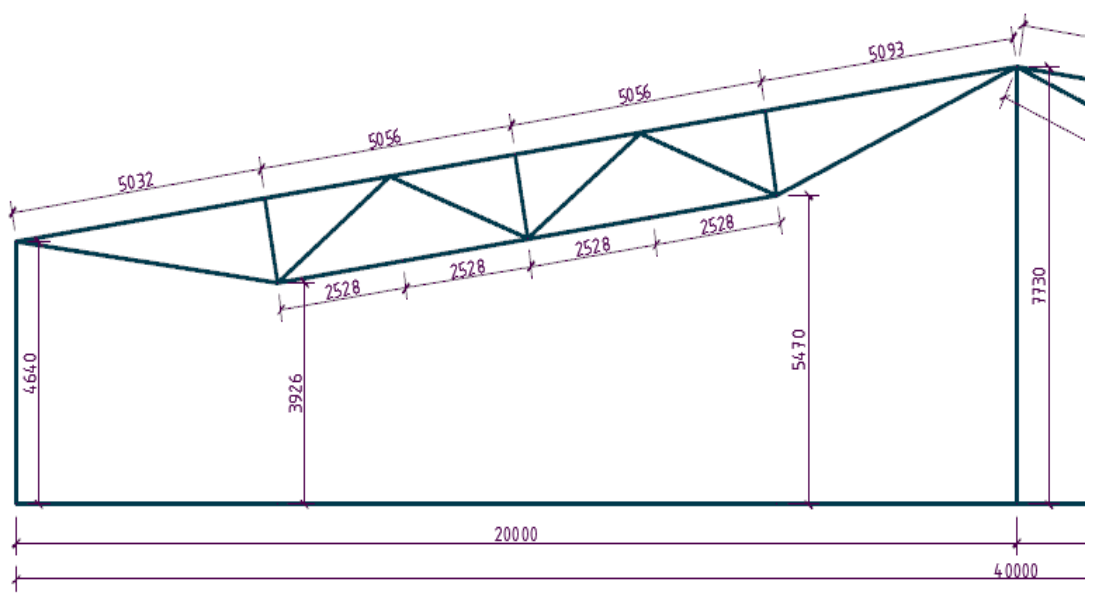

Fig. 2a. The geometric dimensions of the elements truss trusses 


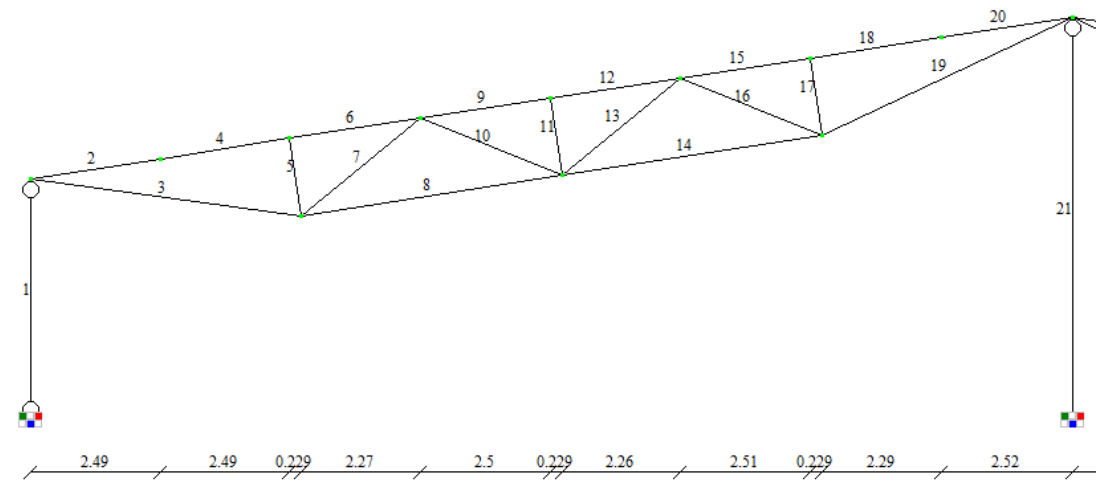

Fig. 2b. Numbering scheme truss elements

The results of the calculation of the determination of the forces and the geometrical dimensions of the trusses are shown in Table 2 and Figure 2, respectively.

Table 2. Estimated efforts in the truss rods when working, taking into account the additional applied load

\begin{tabular}{|c|c|c|c|c|}
\hline \multirow{2}{*}{$\begin{array}{c}\text { Item } \\
\text { number }\end{array}$} & \multirow{2}{*}{$\begin{array}{c}\text { Section } \\
\text { No. }\end{array}$} & \multicolumn{3}{|c|}{ Efforts } \\
\hline & & $\mathbf{N}(\mathrm{t})$ & My(t*m) & $\mathbf{Q z}(\mathbf{t})$ \\
\hline \multirow{5}{*}{3} & 1 & 30.957 & 1.099 & 0.271 \\
\hline & 2 & 30.954 & 1.439 & 0.246 \\
\hline & 3 & 30.950 & 1.746 & 0.222 \\
\hline & 4 & 30.947 & 2.021 & 0.197 \\
\hline & 5 & 30.944 & 2.264 & 0.173 \\
\hline \multirow{5}{*}{4} & 1 & -30.830 & 3.718 & -1.076 \\
\hline & 2 & -30.828 & 3.038 & -1.087 \\
\hline & 3 & -30.826 & 2.351 & -1.099 \\
\hline & 4 & -30.825 & 1.656 & -1.111 \\
\hline & 5 & -30.823 & 0.954 & -1.123 \\
\hline \multirow{5}{*}{5} & 1 & -4.547 & -0.688 & 0.770 \\
\hline & 2 & -4.540 & -0.400 & 0.769 \\
\hline & 3 & -4.533 & -0.112 & 0.768 \\
\hline & 4 & -4.526 & 0.176 & 0.767 \\
\hline & 5 & -4.520 & 0.463 & 0.766 \\
\hline \multirow{5}{*}{6} & 1 & -31.130 & 0.490 & 0.432 \\
\hline & 2 & -31.129 & 0.760 & 0.420 \\
\hline & 3 & -31.127 & 1.022 & 0.409 \\
\hline & 4 & -31.125 & 1.276 & 0.397 \\
\hline & 5 & -31.123 & 1.523 & 0.385 \\
\hline \multirow{5}{*}{7} & 1 & -6.751 & 0.715 & 0.161 \\
\hline & 2 & -6.742 & 0.830 & 0.151 \\
\hline & 3 & -6.733 & 0.937 & 0.140 \\
\hline & 4 & -6.725 & 1.036 & 0.129 \\
\hline & 5 & -6.716 & 1.127 & 0.119 \\
\hline \multirow{5}{*}{8} & 1 & 36.206 & 0.860 & 0.183 \\
\hline & 2 & 36.210 & 1.077 & 0.159 \\
\hline & 3 & 36.214 & 1.263 & 0.136 \\
\hline & 4 & 36.217 & 1.420 & 0.112 \\
\hline & 5 & 36.221 & 1.547 & 0.089 \\
\hline
\end{tabular}

Determination of the geometric characteristics of the cross section of the upper belt truss: 
Cross sectional area

$$
A=18.72 * 2=37.44 \mathrm{~cm}^{2},
$$

Moment of inertia

$$
J_{x}=\left(\frac{0.3 * 40^{3}}{12}+2 * 9 * 0.3 * 19.85^{2}+2 * 0.3 * 18.72^{2} * 2\right) * 2=8293 \mathrm{~cm}^{4}
$$

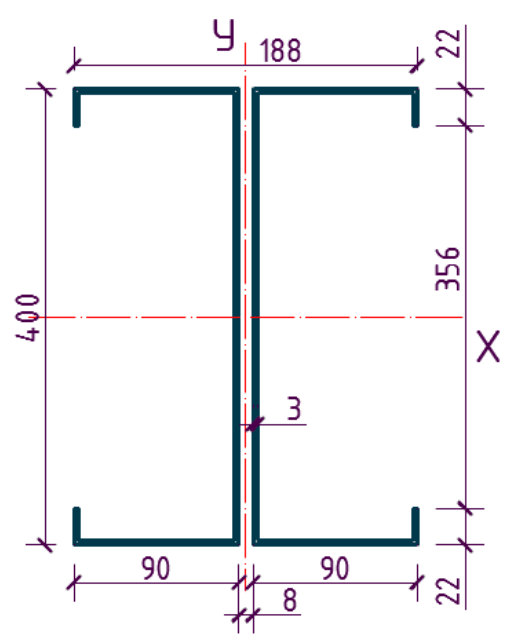

Fig. 3. Section of the upper belt truss trusses

Cross sectional area

$$
A=18.72 * 2=37.44 \mathrm{~cm}^{2},
$$

Moment of inertia

$$
J_{x}=\left(\frac{0.3 * 40^{3}}{12}+2 * 9 * 0.3 * 19.85^{2}+2 * 0.3 * 18.72^{2} * 2\right) * 2=8293 \mathrm{~cm}^{4},
$$

Therefore, the moment of inertia of the C-shaped profile AC-400-90-22-3,0:

The radius of inertia of the section:

$$
J_{x}^{1}=4146.5 \mathrm{~cm}^{4}
$$

$$
i_{x}=\sqrt{\frac{J_{x}}{A}}=\sqrt{\frac{8293}{37.44}}=14.88 \mathrm{~cm},
$$

Conditional flexibility:

$$
\bar{\lambda}_{x}=\frac{l_{x}}{i_{x}} \sqrt{\frac{R_{y}}{E}}=\frac{252.8}{14.88} \sqrt{\frac{335}{2.06 * 10^{4}}}=0.7
$$

We accept according to the joint venture 16.13330.2017 "Steel structures. Updated edition SNiP II-23-81*" buckling coefficient $\varphi=0,93$ 
The stability of the compressed element of the belt in the plane:

$$
\sigma=\frac{N}{\varphi * A}=\frac{44000}{0.93 * 37.44}=1264 \mathrm{~kg} / \mathrm{cm}^{2}<R_{y} * \gamma=3450 * 0.95=3277.5 \mathrm{~kg} / \mathrm{cm}^{2},
$$

Moment of resistance:

$$
W_{x}=\frac{2 J_{x}}{h}=\frac{2 * 8293}{40}=414 \mathrm{~cm}^{3},
$$

Check the strength of rods 2 and 4 (see Figure 2)

$$
\begin{gathered}
\sigma=\frac{N}{A}+\frac{M}{W_{x}}=\frac{35000}{37.44}+\frac{4000 * 100}{414}=1901 \mathrm{~kg} / \mathrm{cm}^{2} R_{y} * \gamma=3450 * 0.95= \\
3277.5 \mathrm{~kg} / \mathrm{cm}^{2}
\end{gathered}
$$

Check the stability of this rod as an eccentrically compressed element.

For this, reduced eccentricity:

$$
m_{l}=\eta * m_{x}
$$

Relative eccentricity:

$$
m_{x}=\frac{M * A}{N * W_{x}}=\frac{400000 * 37.44}{35000 * 414}=1.03,
$$

Conditional flexibility:

$$
\bar{\lambda}_{x}=\frac{492}{14,88} \sqrt{\frac{33,5}{2,06 * 10^{4}}}=1,33,
$$

The ratio of the area of the shelf section to the area of the wall:

$$
\begin{gathered}
\frac{A_{p}}{A_{s t}}=\frac{(9+2,2) * 2,2}{40 * 0,3}=\frac{3,36}{12}=0,28, \\
\eta=\left(1,45-0,05 * m_{x}\right)-0,01\left(5-m_{x}\right) \bar{\lambda}_{x}, \\
\eta=(1,45-0,05 * 1,03)-0,01(5-1,03) * 1,33=1,345, \\
m_{l}=1,345 * 1,03=1,385,
\end{gathered}
$$

Eccentric eccentricity:

Check the stability in the plane of the moment:

$$
\varphi_{\text {in }}=0,42
$$

$$
\sigma=\frac{N}{\varphi * A}=\frac{35000}{0.42 * 37.44}=2226 \mathrm{~kg} / \mathrm{cm}^{2}<R_{y} * \gamma=3450 * 0.95=3277.5 \mathrm{~kg} / \mathrm{cm}^{2},
$$

when using steel grade S350 (S345) according to GOST R 52246-2004.

Determine the bearing capacity of bolts M16 strength class 5.8

During the work of the 1 st bolt on crushing of the connected elements 


$$
N_{c r}^{b}=R_{t m} * \gamma_{t m} * d * \sum t
$$

Galvanized steel:

Wall thickness - $2 \mathrm{~mm}$.

$$
N_{c r}^{b}=6450 * 0.9 * 1,6 * 0,4=3715 \mathrm{~kg},
$$

Wall thickness $-2.5 \mathrm{~mm}$.

$$
N_{c r}^{b}=6450 * 0.9 * 1,6 * 0,5=4644 \mathrm{~kg},
$$

Wall thickness $-3.0 \mathrm{~mm}$.

$$
N_{c r}^{b}=6450 * 0.9 * 1,6 * 0,6=5573 \mathrm{~kg},
$$

when using steel grade S350 (S345) according to GOST R 52246-2004.

The fillet in the truss construction $-\mathrm{t}=8 \mathrm{~mm}$ is made of S255 steel according to GOST 27772-2015.

Bearing capacity of the 1 st bolt to cut:

$$
N_{c r}^{b}=R_{c r}^{b} * \gamma_{b} * A^{b} * n_{c r}=2000 * 0,9 * 2,01 * 2=7236 \mathrm{~kg},
$$

regardless of the thickness of the walls of the belts and grille farm.

where $R_{c r}^{b}$ and $R_{t m}$ are the calculated resistances of the bolts and the elements connected by them

$d$ - is the outer diameter of the bolt rod;

$A^{b}$ - the estimated cross-sectional area of the bolt;

$\sum t$ - is the smallest total thickness of elements collapsible in one direction;

$n_{c r}$ - the number of calculated cuts of one bolt;

$\gamma_{b}$ - the ratio of the working conditions of the connection. For a multi-bolt compound in the calculations for shear and collapse for accuracy class B and C, $\gamma_{b}=0.9$.

In the support unit of the upper belt, 12 bolts were designed. The force in the upper belt, taking into account the additionally applied load of $700 \mathrm{~kg}$ in each node of the lower belt, is $N(2-4)=-35$ tons.

The required number of bolts in this connection with a diameter of M16 of strength class 5.8:

$$
n_{b}=\frac{N_{2-4}}{N_{\min }^{b}}=\frac{35000}{5573}=6,2 \text { bolts }
$$

In the node the number of bolts is designed 12 pcs.

In the assembly joint of the upper belt (middle of the truss) $11 \mathrm{M} 16$ bolts of strength class 5.8 were designed. Force in the joint zone $N g=-44$ tons.

The number of bolts, sufficient for the perception of this effort, taking into account the additional load in the nodes of the lower zone by 0.7 tons.

$$
n_{b}=\frac{44000}{5573}=8 \text { bolts, }
$$

In reality, 11 units are designed in the unit.

The lower belt "works" on stretching and is made of a C-shaped galvanized paired profile. 
Cross sectional area

$$
A=11,5 * 2=23 \mathrm{~cm}^{2},
$$

The most loaded element of the lower belt is (taking into account the additionally applied load) of panel number 8 and 14. The force will be $N_{8-14}=+40$ tons.

The strength of the elements of the lower belt:

$$
\sigma=\frac{N}{A}=\frac{40000}{23}=1739 \mathrm{~kg} / \mathrm{cm}^{2}<R_{y} * \gamma=3450 * 0.95=3277.5 \mathrm{~kg} / \mathrm{cm}^{2},
$$

In node 2 (see the section KMS, sheets 10, 11, 12), the lower belt is attached to the $8 \mathrm{~mm}$ thick nodal cut made of steel S255 according to GOST 27772-2015 with 12 bolts M16 of strength class 5.8 .

The required number of bolts in the connection, subject to the additionally applied load of 0.7 tons in the nodes of the lower belt

$$
n_{b}=\frac{N_{5-14}}{N_{\min }^{\mathrm{b}}}=\frac{40000}{4644}=8,6 \text { bolts }
$$

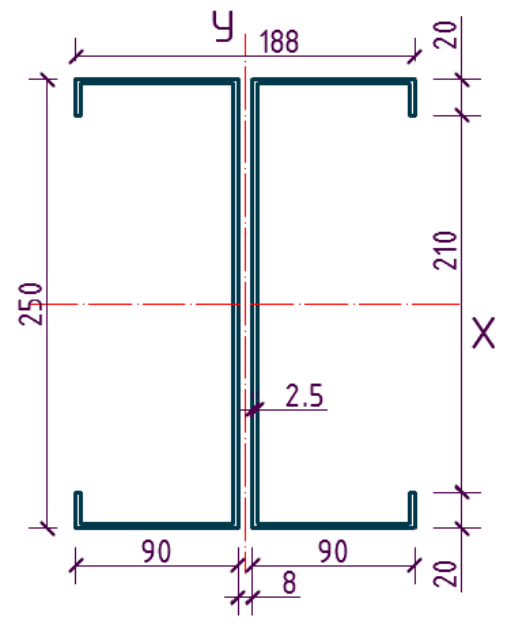

Fig. 4. Cross-section of the upper belt truss trusses

12 pieces are designed in the farm node.

The greatest effort in the lattice trusses with the additionally applied load occurs in braces 7 and 16:

$N_{7,16}=-8$ tons.

These elements are made of C-shaped galvanized twin profiles FR-6 according to the project. 


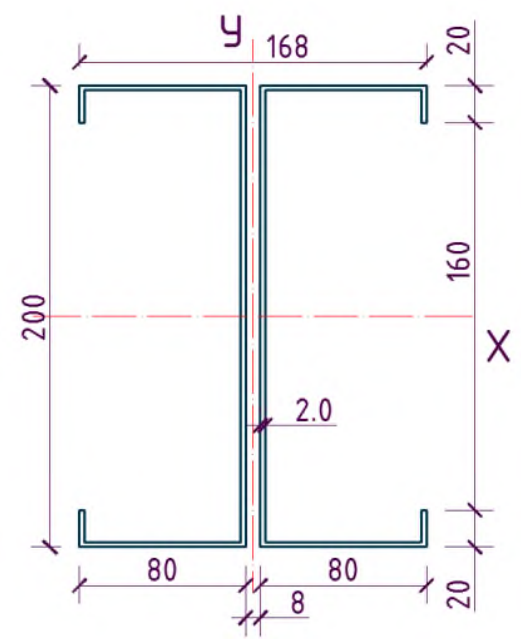

Fig. 5. Cross-section racks and braces truss trusses

Cross sectional area

$$
A=7,84 * 2=15,68 \mathrm{~cm}^{2},
$$

Radius of inertia about $X$ axis: $i_{x}=7,95 \mathrm{~cm}$.

Estimated length: $l_{x}=293,9 \mathrm{~cm}$.

Conditional flexibility:

$$
i_{x}=\frac{293,9}{7,59} * \sqrt{\frac{33,5}{2,06 * 10^{4}}}=1,49,
$$

Buckling coefficient: $\varphi=0,82$

The stability of the compressed element of the belt in the plane:

$$
\sigma=\frac{N}{\varphi * A}=\frac{8000}{0.82 * 15.68}=622,2 \mathrm{~kg} / \mathrm{cm}^{2}<R_{y} * \gamma=3450 * 0.95=3277.5 \mathrm{~kg} / \mathrm{cm}^{2},
$$

Lattice of farms: both racks and braces has a big stock of the bearing ability. The braces are attached to the nodal gaps with 6 M16 bolts of strength class 5.8.

The required number of bolts for mounting braces

$$
n_{b}=\frac{8000}{3715}=2,2 \text { bolts, }
$$

In the connection, 6 pcs are designed.

Efforts in all three racks of the truss with additional load are

$$
N_{5,11,17}=5 \text { tons. (FS-3, FS-4). }
$$

The FS-3 racks are made (projected) of the same section as bracing.

The FS-4 racks have a wall thickness of $\mathrm{t}=2.5 \mathrm{~mm}$, therefore the cross-sectional area will be:

$$
A=20,00 \mathrm{~cm}^{2}
$$


So, the FS-3 racks have a lower carrying capacity, so their stability will be:

$$
\bar{\lambda}_{x}=\frac{150}{7,95} \sqrt{\frac{33,5}{2,06 * 10^{4}}}=0,75,
$$

Buckling coefficient: $\varphi=0,9$, then:

Element stability:

$$
\sigma=\frac{N}{\varphi * A}=\frac{5000}{0.9 * 15.68}=354,3 \mathrm{~kg} / \mathrm{cm}^{2}<R_{y} * \gamma=3450 * 0.95=3277.5 \mathrm{~kg} / \mathrm{cm}^{2},
$$

Racks are attached to the nodal gaps 4 M16 bolts strength class 5.8.

Taking into account the additionally applied load, the required number of bolts for fastening the struts to the gussets is:

$$
n_{b}=\frac{5000}{3715}=1,4 \text { bolts, }
$$

Consequently, when an additional load of $700 \mathrm{~kg}$ is applied to the lower nodes of the truss ( 3 knots), the carrying capacity of the truss trusses will be provided.

We will develop a variant of the suspension device to ensure universal mounting of the additionally applied load to the truss assembly.

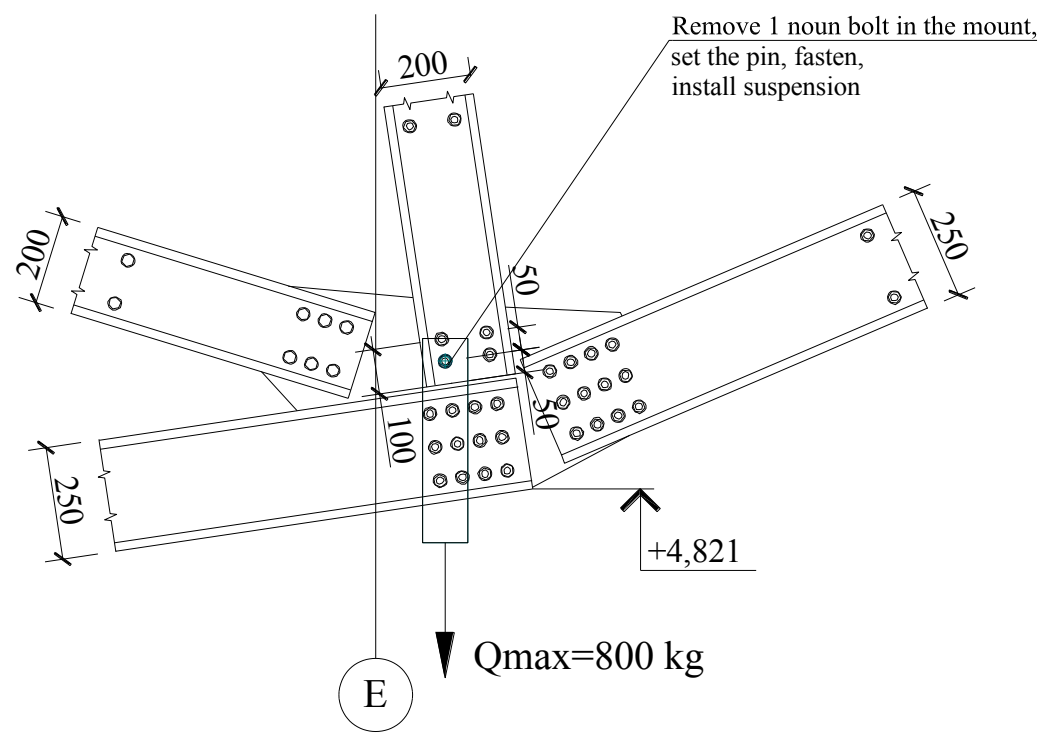

Fig. 6. Node lower farm truss with indication of where the additional load is applied

The designed suspension must meet the requirements of universality for the further installation of suspension equipment. Therefore, we use a loop made of sheet steel. Such fastening will allow the load to be applied to the node in any convenient way (hook, sling, etc.) and to ensure the attachment mobility in the plane of load application.

Technology suspension device is as follows:

- $\quad$ dismantle one existing bolt in the rack mount, as shown in Figure 6; 
- $\quad$ install M16 stud in the hole;

- $\quad$ install washers on the two sides of the pin, nuts, lock nuts;

- tighten the connection with a torque wrench to a standard value corresponding to strength class 5.8 ;

- install 2 intermediate nuts, washers on both ends of the stud, install the suspension, the remaining 2 washers and nuts, tighten the connection on each side of the stud.

Let's make the specification of materials for the device of one suspension, we will present the results in table 3 .

Table 3. Specification of materials for the device 1 suspension

\begin{tabular}{|c|c|c|}
\hline Title of the document & Designation & Amount \\
\hline GOST 7772-2015 & Sheet -4x100x1134, S255 & 1 \\
\hline GOST 2590-2006 & Hairpin M16,09G2S, L=270 & 1 \\
\hline GOST 11371-78 & Washer 2.16.01.08kp.016 & 6 \\
\hline GOST 5915-70 & Nut M16-6H.5 (S24) & 8 \\
\hline
\end{tabular}

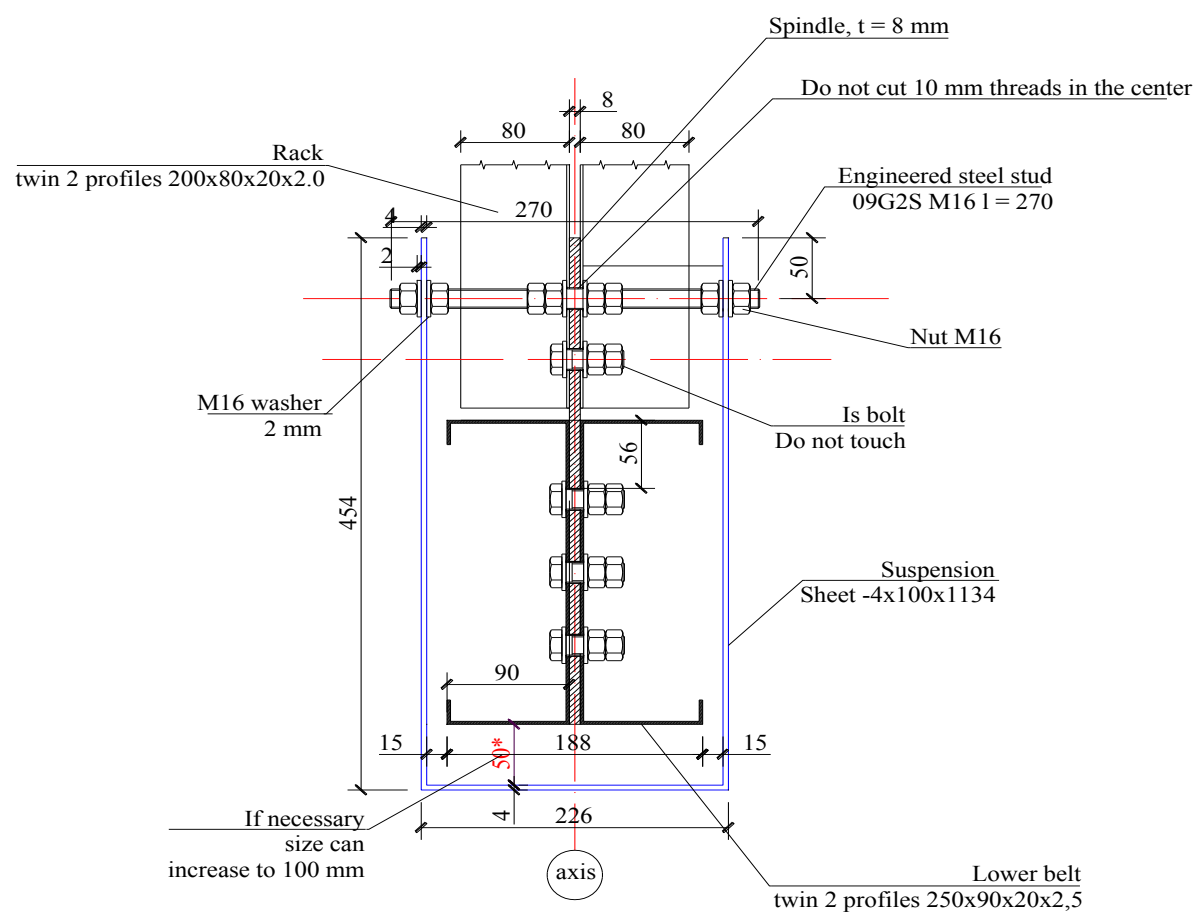

Fig. 7. Option of attaching an additional load through a suspension device in a truss assembly

\section{Conclusion}

As a result of the study, the following were found:

1. It is possible to apply additional load in the trusses.

2. The maximum additional nodal load should not exceed $800 \mathrm{~kg}$ due to the carrying capacity of the bolted joint of the upper belt in the middle of the span. 
3. The option of attaching an additional load to the lower nodes of the truss is designed in Figure 6 of this study.

\section{Reference}

1. SP 70.13330.2012 the Bearing and enclosing structures. The revised edition Construction Norms and Regulations 3.03.01-87 (with Changes № 1, 3).

2. SP 16.13330.2011 Updated version of SNiP II-23-81 "Steel structures".

3. SP 20.13330.2016 “SNiP 2.01.07-85*. Loads and Impacts".

4. SP 17.13330.2011 The updated version of the Roof Construction Regulations and Regulations II-26-76.

5. SP 13-102-2003 "Rules for inspection of supporting building structures of buildings and structures”. M., 2003.

6. GOST 31937-2011 Buildings and facilities. Rules of inspection and monitoring of technical condition.

7. Working documentation "Design of buildings and temporary facilities for the preparation and conduct of the World Cup in 2018 in the Russian Federation. Media Center 40x70m, Saransk", sections KM, KMD, KMS. 